\title{
Uso do Scratch no ensino de programação em Ponta Porã: das séries inicias ao ensino superior
}

\author{
Esteic Janaina S. Batista ${ }^{1,2}$, Amaury A. Castro Jr. ${ }^{1,2}$, Sávio Vinicius \\ Cantero $^{1,2}$, Cintia Adriana C. Bogarim ${ }^{1}$, Andreia A. Larrea ${ }^{1}$ \\ ${ }^{1}$ Universidade Federal de Mato Grosso do Sul - Campus Ponta Porã (CPPP) \\ Rua Itibiré Vieira, s/n - Residencial Julia Oliveira Cardinal BR 463 - Km 4,5 \\ ${ }^{2}$ Bolsistas do Programa de Educação Tutorial - PET/SESu/MEC \\ \{esteicejanaina, amaury.ufms, savio.cantero, cintiaadrianab, \\ larreaandreia\}@gmail.com
}

\begin{abstract}
Many studies have shown the importance of teaching and learning programming in different areas, not limited only to computer courses, to develop skills that are essential to any area as the logical reasoning. It is necessary then to be taught to digital proficiency, including computational thinking from elementary school through appropriate tools for the majority of the public. This article shows how the programming language Scratch blocks was used in different education levels in the early grades and end of elementary school, high school and higher education, from the experience reports.
\end{abstract}

Resumo. Várias pesquisas já demonstraram a importância do ensino e aprendizagem da programação em diferentes áreas, não se limitando apenas aos cursos de computação, por desenvolver habilidades que são essenciais para qualquer área como o raciocínio lógico. Torna-se necessário, então, que seja ensinado a proficiência digital, incluindo o pensamento computacional desde o ensino fundamental, por meio de ferramentas adequadas para o maioria do público. Este artigo apresenta como a linguagem de programação em blocos Scratch foi utilizada em diferentes escolaridades nas séries iniciais e finais do ensino fundamental, ensino médio e no ensino superior, a partir dos relatos de experiência.

\section{Introdução}

O ensino focado apenas na utilização das tecnologias não é mais suficiente, pois diferente da geração $X$ que conviveu com tecnologias digitais já na sua fase adulta na maioria dos casos, principalmente no contexto brasileiro, a geração Y já pôde vivenciar desde cedo com as tecnologias e chega à graduação não mais satisfeitos com os equipamentos disponível (ou não) em sala de aula [Tori 2016], e chega então a geração $\mathrm{Z}$, considerados nativos digitais, e precisam ser orientados no uso destas novas tecnologias.

No campo da educação, as crianças da geração Y nascidas entre 2001 e 2007 são consideradas da geração F5 que, segundo [Souza 2015] corresponde às iniciais de Full time (todo tempo), Feed (alimentação), Filtro, Foco, Flexibilidade. A geração F5 nasceu em meio a expansão da banda larga, das redes sociais e das tecnologias touchsreen e 
necessitam estar conectadas todo momento, são alimentadas por muitas informações disponíveis online, mas conseguem selecionar o que lhe interessam e se aprofundar nelas, com flexibilidade em transitar entre diversos assuntos.

Torna-se necessário capacitar a geração X em que atuam como educadores das gerações posteriores, visto que na maior da sua vida profissional tiveram pouco contato ou nenhum destas tecnologias. Quando as pessoas do início da geração Y chega ao mercado de trabalho são considerados inovadores e empreendedores, mas apesar da tecnologia ser algo já natural para eles, ainda não vêem sentido em utilizá-las na aula, por outro lado as que nasceram no final da geração $\mathrm{Y}$ chegam na Universidade precisando de novos desafios que os capacitem para lidar com as habilidades exigidas pelo novo mercado de trabalho, como trabalho em equipe, raciocínio lógico e uso direcionado destas tecnologias. A geração Z e F5 já tem a tecnologia como algo indispensável, e como nasceram convivendo com estas novas tecnologias, imersos em informações, precisam na sua vida escolar, desafios que utilizem estas tecnologias que são naturais a eles.

Pensando em como articular as tecnologias em sala de aula frente as diferentes gerações, podemos começar ressaltando a visão de Paulo Freire, importante educador brasileiro, que acreditava que a escola deveria ser um espaço onde favorecesse a inquietação dos alunos, onde despertaria sua criatividade e curiosidade, levando-o a investigação e assim formando seu conhecimento [Freire 2014]. Mas antes dele, temos Jean Piaget, criador da teoria do construtivismo, que em geral defende que o conhecimento não é algo pronto e acabado, ele se dá pela interação com o meio físico e social. Dessa forma propõe que o estudante participe ativamente do próprio aprendizado, mediante a experimentação, pesquisa em grupo, estimulo a dúvida e o desenvolvimento do raciocínio, dentre outros procedimentos [Becker 1994].

Posteriormente, outro pesquisador influenciado por Piaget e que carregava a mesma visão de Freire sobre a importância de o estudante saber ler o mundo, criador da linguagem LOGO e da teoria do construtivismo, onde o indivíduo através do computador constrói seu próprio conhecimento [Cysneiros 2008]. Nesta teoria, a construção do conhecimento acontece de duas formas: quando o indivíduo cria um objeto no computador, como um jogo ou um programa, e quando ele cria algo do seu interesse e por isso torna-se mais motivado, pois para Papert, o envolvimento afetivo torna a aprendizagem mais efetiva [Resnick, Ocko e Papert 1988].

Pesquisador do MIT (Massachusetts Instituteof Technology) e influenciado por Papert, Mitchel Resnik defende a importância do aprendizado da programação por todos, por desenvolver uma série de habilidades no indivíduo e por a programação ser algo cada vez mais necessário na vida das pessoas, mesmo estas não trabalhando sendo da área da programação e acredita que elas deveriam aprender desde crianças, ideologia implementada no movimento pela programação (codermovement).

Nestas ideologias, Mitchel Resnik e outros pesquisadores do MIT criaram a linguagem Scratch, baseada na linguagem LOGO de Papert para o ensino de programação de uma forma atraente e divertida [Maloney et. al. 2010].

O objetivo deste trabalho é apresentar como a linguagem Scratch foi utilizada nas séries iniciais e finais do ensino fundamental, ensino médio ou técnico e ensino superior. Espera-se que assim, este trabalho possa servir como base para futuras 
V Congresso Brasileiro de Informática na Educação (CBIE 2016)

Anais do XXII Workshop de Informática na Escola (WIE 2016)

pesquisas e aplicações da ferramenta em sala de aula, como forma de incentivar o conhecimento da programação.

A primeira seção do trabalho descreve a ferramenta Scratch. As próxima seções descrevem as metodologias aplicadas em cada uma destas escolaridades, os objetivos para cada um dos públicos, percalços e alguns resultados obtidos, e apresentaremos alguns trabalhos relacionados sobre o uso do Scratch para cada escolaridade já publicados nos anais do Workshop de Informática na Educação (WIE), Simpósio Brasileiro de Informática na Educação (SBIE) e Revista Brasileira de Informática na Educação (RBIE). A última seção fará algumas considerações gerais sobre o uso da ferramenta Scratch no ensino.

\section{O Scratch}

O Scratch é uma ferramenta de programação em blocos para criar estórias animadas, jogos e objetos de aprendizagem. Ele foi lançado em 2007 pelo grupo Lifelong Kindergarten (jardim de infância ao longo da vida) no Media Lab do Instituto de Tecnologia de Massachusetts (MIT) dos Estados Unidos, coordenado pelo pesquisador Mitchel Resnick.

É uma ferramenta gratuita desenvolvida para crianças e adolescentes, mas que vem sendo utilizado por pessoas de diferentes faixas etárias, que permite que seja aplicado em uma série de diferentes projetos pedagógicos, que possibilita crianças e jovens a aprenderem programação desde cedo, possibilitando ser aplicada em diferentes disciplinas de forma multidisciplinar [Batista et. al. 2015].

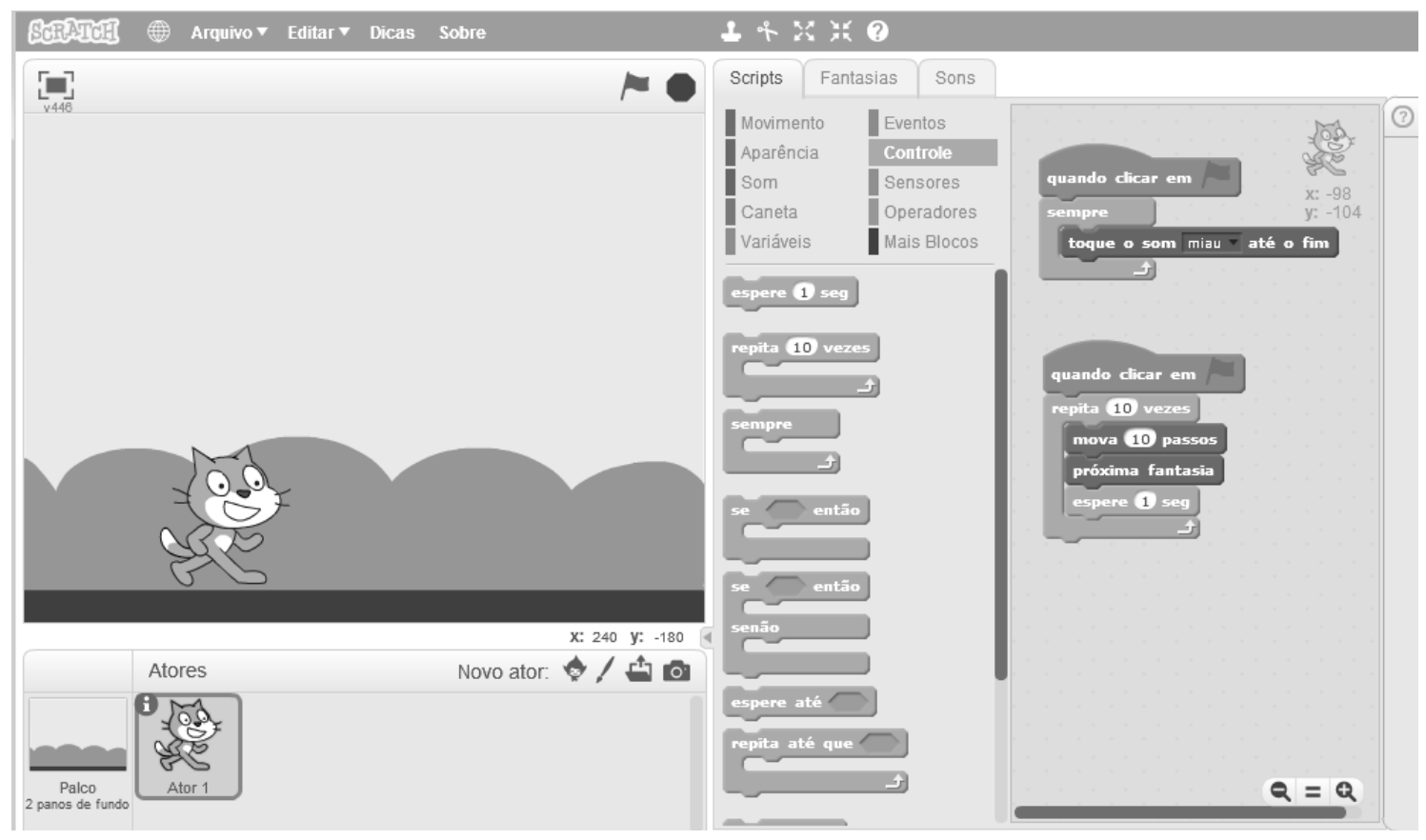

Figura 1. Interface do Scratch 2

Resnick defende que as crianças terão que enfrentar problemas inesperados no futuro, que necessitarão de criatividade para resolvê-los e para isso terão que projetar soluções inovadoras. Para desenvolver esta aprendizagem criativa, ele apresenta a abordagem 4P's, que são correspondem às iniciais de Projects, Peers, Passion, e Play, 
V Congresso Brasileiro de Informática na Educação (CBIE 2016)

Anais do XXII Workshop de Informática na Escola (WIE 2016)

fortemente inspirado no teoria do construtivismo que aborda a construção do conhecimento da crianças através de projetos em colaboração com os colegas [Resnick 2014]. A abordagem quatro P's descreve:

a) Projetos (Projects): as pessoas aprendem melhor quando eles estão trabalhando ativamente em projetos significativos, na geração novas ideias, projetando protótipos.

b) Pares (Peers): o conhecimento se constrói a partir da interação entre pessoas, projetos em grupos/pares que possibilitem o compartilhando de ideias e na colaboração no trabalho uma da outra.

c) Paixão (Passion): quando as pessoas trabalham em projetos que tem interesse, ela persiste em frente aos erros, tenta até conseguir o resultado, e assim aprendem mais neste processo.

d) Jogar (Play): aprender envolve experimentação, tentar coisas novas, mexer com materiais, testar, jogar, reproduzir, assumir riscos, tentar novamente.

O Scratch é uma ferramenta que permite trabalhar esta abordagem, Baseado na linguagem LOGO, ele possui códigos simples para comandar o personagem por blocos, que permitem serem encaixados para criar uma aplicação, o que lembra os brinquedos de encaixar Lego, baseado no conceito de drag-and-drop (arrastar e largar) [omitido para revisão]. O Scratch permite criar estórias animadas, jogos e objetos de aprendizagem através de seus comandos que são organizadores por suas características em cores diferentes para evitar erros (Figura 1). Ele é disponibilizado para Windows, Linux, Mac e online no site oficial do Scratch.

Outras ferramentas foram lançadas pelo MIT, dentre eles o ScratchJr, similar ao Scratch, mas voltado para crianças de 5 a 7 anos. A ferramenta não possui texto nos seus comandos, visto que nesta faixa etária as crianças não possuem total domínio da leitura. No entanto, ela permite criar animações, alguns jogos e resolver problemas (Figura 2). O Scratch Jr é disponível para tablets da Apple ou com o sistema Android.

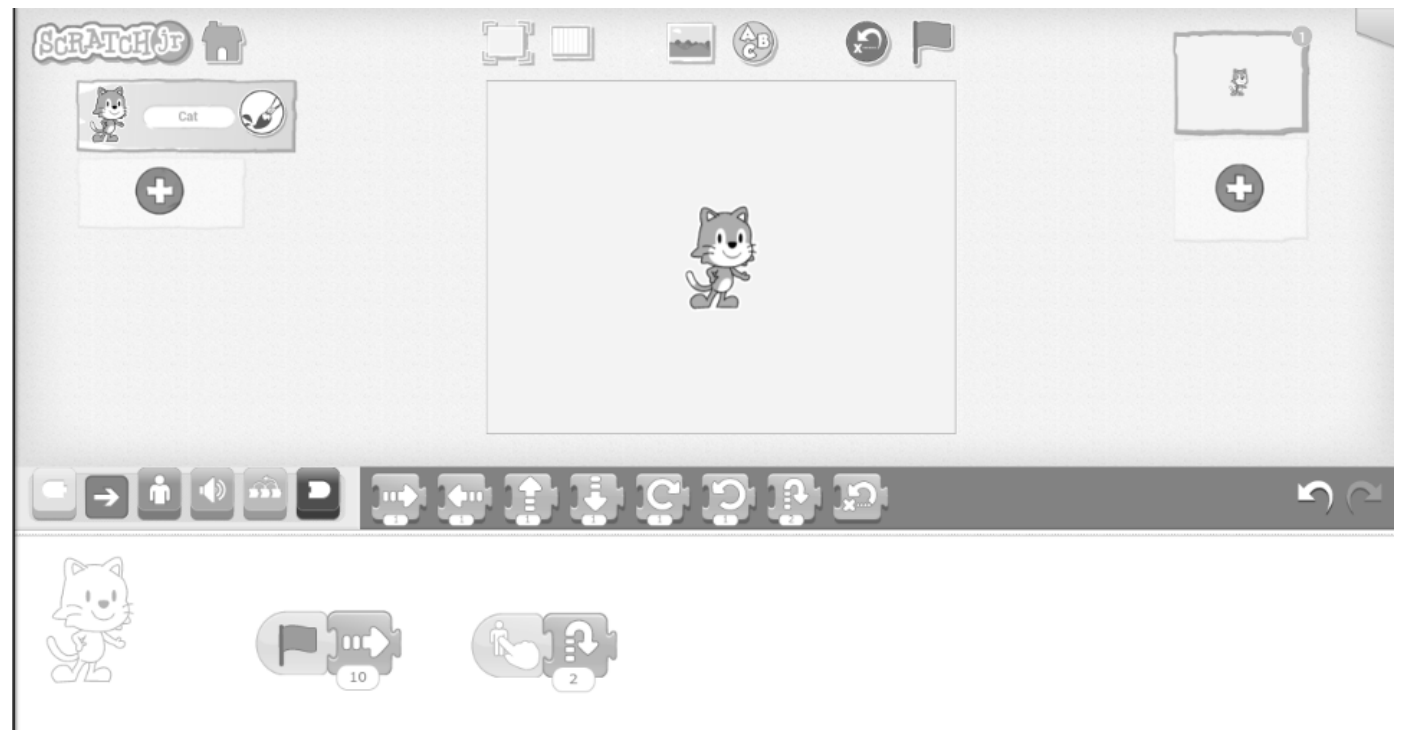

Figura 2. Interface do ScratchJr 
No Scratch 2 na versão para Windows, o conjunto de blocos "Mais Blocos" há a opção de incluir extensão de kits de robótica, como o Lego Wedo 1 e 2, e também com placa microcontroladoras, como o RaspBerry Pi. No entanto, no Brasil, o micocontrolador Arduino é mais acessível para algumas instituições. Como o Scratch 1 é código livre, foi desenvolvida uma versão do Scratch, conhecida como Scratch para Arduino (S4A), desenvolvido por um grupo da CitiLab, que permite criar jogos que se comunicam externamente com a placa microcontroladora (Figura 3 ).

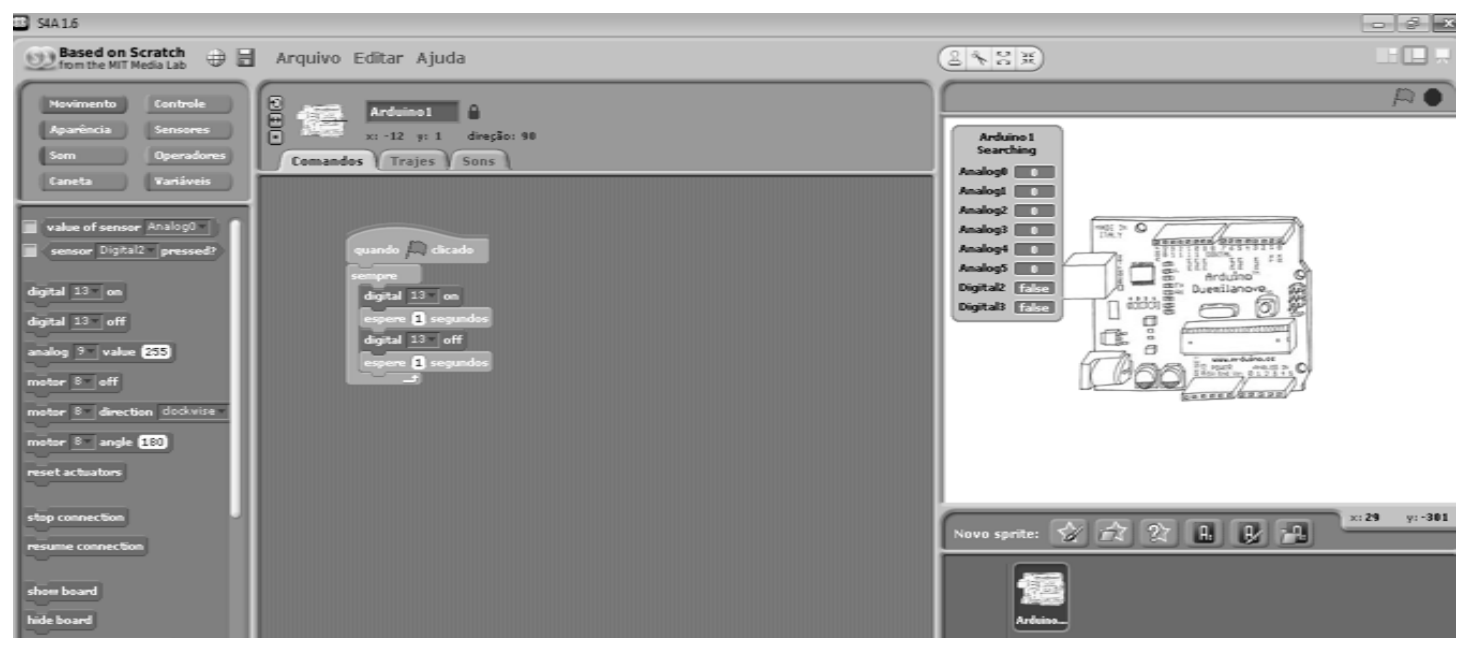

Figura 3. Interface do S4A

\section{Scratch no Ensino Fundamental}

Esta seção apresentará a aplicação do Scratch no ensino fundamental, há alguns trabalhos dentro dos eventos do Informática na Educação que avaliaram a aplicação, dentre eles, um estudo de caso de [von Wangenheim et. al. 2014] que obteve como resultados o interesse dos alunos pela programação e apresentou a possibilidade da integração do Scratch no currículo existente do ensino fundamental e no trabalho de [Oro et.al. 2015] que teve como foco uma Olimpíada de programação com o Scratch. Apresentaremos, então, em seguida, nossa experiência e algumas observações.

\subsection{Séries iniciais}

Foi realizado um projeto de extensão de robótica com as séries iniciais do Ensino Fundamental em uma escola pública na cidade de Ponta Porã - MS, correspondente ao primeiro e segundo ano do regime de nove anos. Participaram do projeto uma acadêmica de bacharelado em Sistemas de Informação, duas de licenciatura em Pedagogia, e as professoras regentes com as turmas que estavam realizando o projeto, e dois professores gerenciadores da sala de tecnologia da escola.

O objetivo deste projeto de robótica foi preparar os alunos para a realização da OBR (Olimpíada Brasileira de Robótica) na modalidade teórica. A prova consiste em questões que trabalham com o raciocínio lógico das crianças. Nas aulas iniciais do projeto após dinâmicas para explicar sobre o conceito de um robô de forma lúdica com o apoio de demonstrações de robôs montados com o kit Lego EV3, foi proposta uma atividade que consistia em colorir um desenho de robô impresso no papel e dar um nome a eles. Estes desenhos foram transformados em imagens e desenvolvida uma animação deles no Scratch pelas acadêmicas (Figura 4). 
V Congresso Brasileiro de Informática na Educação (CBIE 2016)

Anais do XXII Workshop de Informática na Escola (WIE 2016)

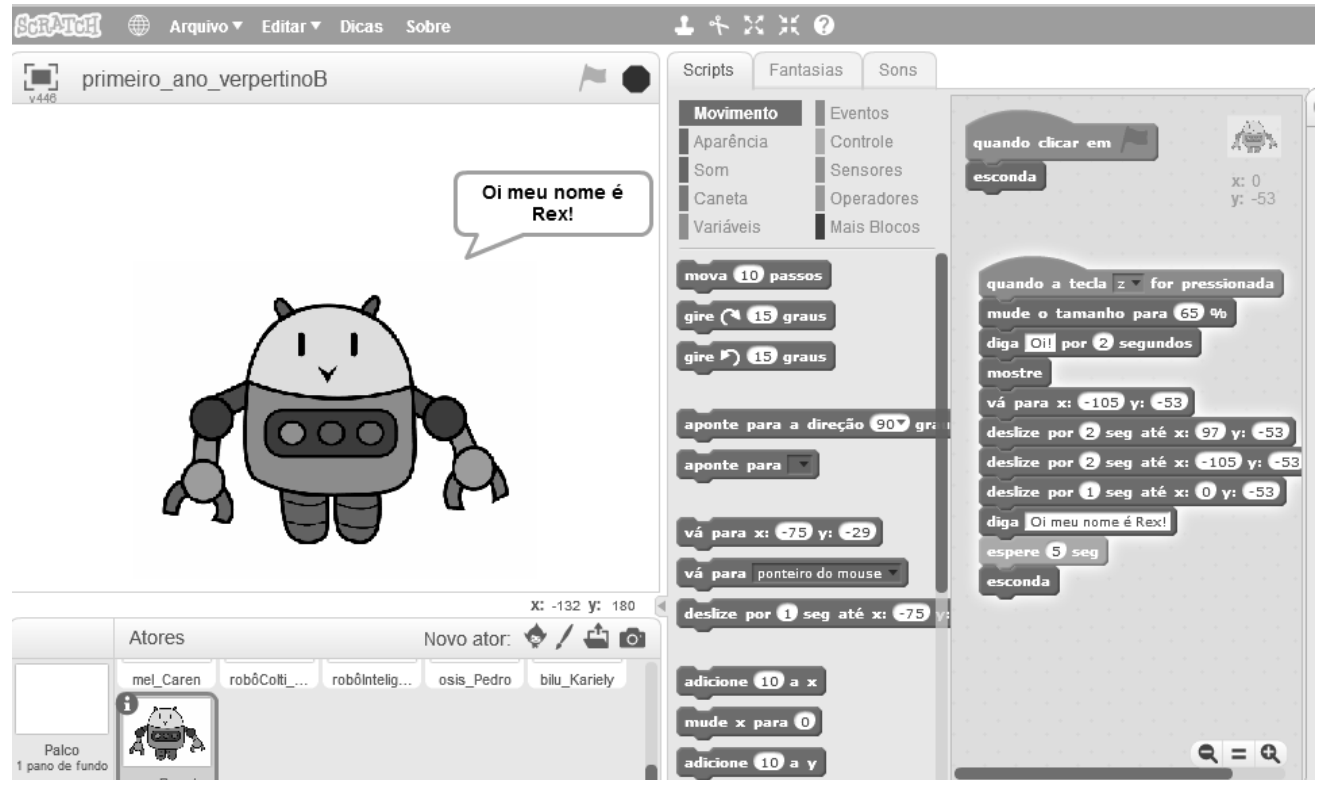

Figura 4. Animação com os robôs no Scratch

Posteriormente, foi utilizado o ScratchJr para que as crianças programassem suas próprias estórias. Foram utilizados quatro tablets com o sistema Android para o projeto, e foram formados quatro grupos com cerca de cinco alunos. Para a explicação dos comandos foi utilizado no computador o programa BlueStacks, simulador do Android, para que todos os estudantes pudessem acompanhar.

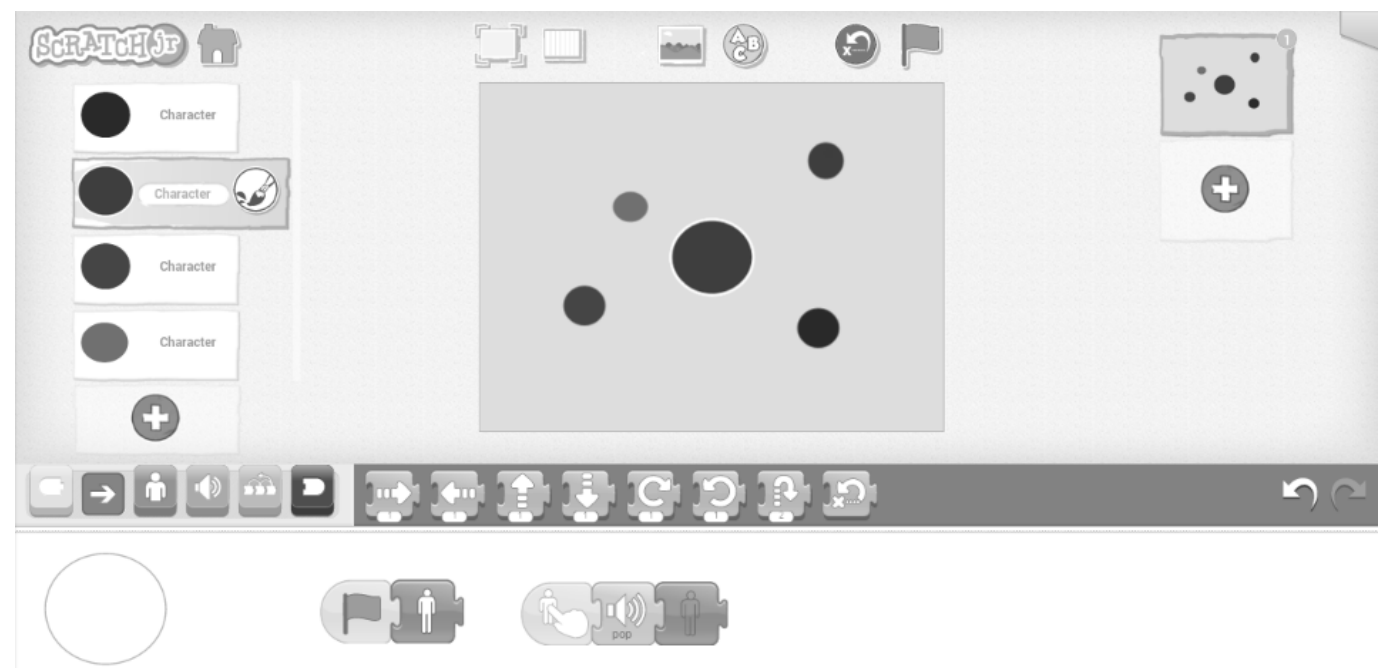

Figura 5. Jogo "estourando bolas" no ScratchJr

Foi proposto que o grupo desenvolvesse um jogo que foi intitulado como "estourando bolas", que consistia em fazer a bola aparecer quando começasse o jogo e desaparecer quando o usuário tocasse nela (Figura 5). Cada integrante desenhou e pintou sua bola no editor do ScratchJr e programou. Outra atividade proposta foi eles recriarem uma fábula contada pela professora no Scratch,em que eles puderam trabalhar com cenários. Outros projetos estão sendo propostos baseado no livro oficial do ScratchJr de forma a manipular outros comandos ainda não explorados [Bers e Resnik 2016]. 
Observou-se que ao longo do projeto, as crianças passaram a trabalhar mais o grupo, visto que no inicio elas queriam monopolizar o dispositivo, e aprenderam a dar a vez ao colega, e acabam ajudando o colega do grupo que estava com mais dificuldade. Quando um grupo terminava a atividade proposta primeiro que os outros, eles ajudavam os outros grupos a terminarem a atividade proposta. Toda aula eles resolviam de três a cinco questões da OBR de edições anteriores, e notou-se que eles passaram a ter mais facilidade para responder as questões.

\subsection{Séries finais}

A ferramenta Scratch foi utilizada com alunos das turmas do sexto e sétimo ano do ensino fundamental de uma escola particular. No início do projeto eles não tinham conhecimento de programação e o Scratch foi escolhido justamente por sua facilidade de manuseio. Foram ministradas aproximadamente quarenta horas aulas distribuídas em 2 meses.

O plano de trabalho seguiu uma sequência começando pelo básico, como: movimentações, troca de trajes e troca de planos de fundo, estimulando o entendimento do ambiente Scratch e a produção de animações simples. Posteriormente foram introduzidas as estruturas de controle, como: enquanto, se então - senão, repita, entre outros, visando a melhoria dos códigos e estimulando a criação de jogos simples. Para aperfeiçoamento dos jogos, foram introduzidas as noções de variáveis e de sensores, como: movimentos do mouse, teclas, cores na tela, distância entre objetos, entre outros. Um dos jogos desenvolvidos pelos alunos foi um jogo da Dengue que consistia em achar possíveis focos de mosquitos da dengue, o que abrangeu a disciplina de biologia.

Posteriormente foi utilizado o Scratch para Arduino (S4A) onde um dos projetos foi a criação do projeto de semáforo com leds. A noção de programação adquirida anteriormente trouxe grande facilidade aos alunos na hora de programar o Arduino.

\section{Scratch no Ensino Médio e Técnico}

A aplicação do Scratch no ensino médio foi em oficinas oferecidas para um campus do Instituto Federal durante a Semana da Tecnologia e Semana do Meio Ambiente para os estudantes do ensino médio com técnico integrado em informática e em agricultura. Por contraste, a maioria dos estudantes eram ingressantes dos cursos de informática e cerca de $20 \%$ de agricultura, ou seja, tinham pouca ou nenhuma experiência com programação.

Na Semana de Tecnologia foi oferecida uma oficina de oito horas durante a manhã e a tarde, onde foi explicado sobre cada conjunto de blocos e propostas algumas atividades, dentre elas: estória sincronizadas por mensagens, agenda (Figura 6) e mini editor de desenhos. 


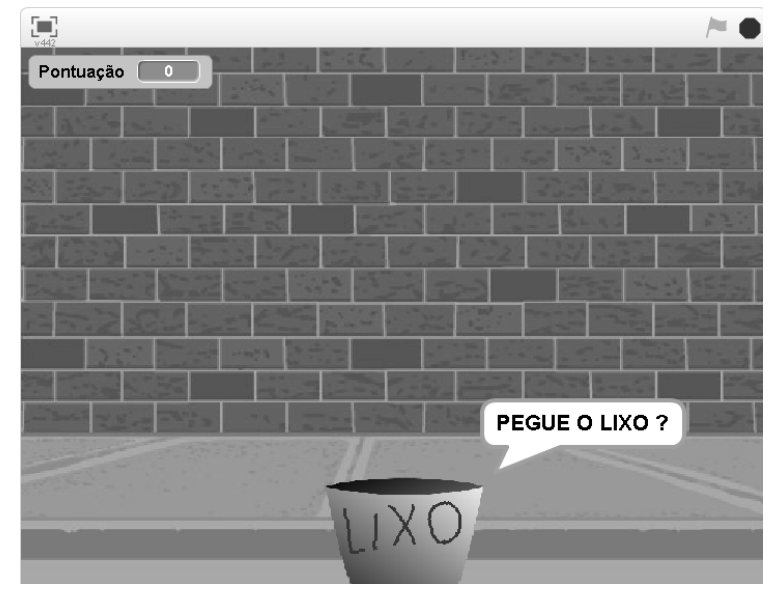

Figura 6. Jogo sobre o Lixo

$\mathrm{Na}$ Semana do Meio Ambiente a carga horário da oficina também foi de oito horas, sendo 4 horas em um dia, e outras 4 no dia posterior. No primeiro dia foi explicado sobre os comandos do Scratch e no dia posterior os estudantes desenvolveram animações e jogos na temática do meio ambiente (Figura 6).

Observou-se queos alunos de informática interligaram com conceitos de algoritmos visto no curso e pode-se relacionar o que eles ainda não tinha visto,como vetor, com a lista do Scratch, por exemplo. Os alunos de agricultura não tiveram dificuldades no desenvolvimento dos jogos, por ser uma ferramenta intuitiva, que oferece ajuda na sua própria interface.

\section{Scratch no Ensino Superior}

Foi ofertado um curso de Scratch de 20 horas para os acadêmicos do curso de licenciatura em Pedagogia e Matemática. O curso aconteceu no modo presencial e virtual utilizando os recursos e-learning e da Educação a Distância (EaD). Utilizou-se a versão 2 da ferramenta Scratch para a oficina. Criou-se uma sala no Ambiente Virtual de Aprendizagem (AVA) Moodle para o curso, onde foi estruturado com tópicos de apresentação da ferramenta, interface, movimentos, aparência, caneta, variáveis e lista, controles, eventos, operadores e blocos. Foram propostas diversas atividades que abordassem o conteúdo do curso, que eram submetidas via Moodle.

A avaliação final do curso foi um projeto no qual os acadêmicos deveriam criar um objeto de aprendizagem utilizando o Scratch. O curso foi importante, pois os acadêmicos já puderam ter contato com estas ferramentas na graduação, e poderão utilizar em sala de aula, visto que a maioria dos formandos destes cursos tornam-se professores do ensino básico.

Para os acadêmicos de Sistemas de Informação e Ciência da Computação foi ofertada uma oficina de oito horas, a maioria dos participantes eram ingressantes dos cursos e alguns veteranos que iriam auxiliar em atividades de extensão que utilizariam o Scratch. As atividades propostas foram similares a do curso completo, em números menores, devido a carga horária. O evasão em cursos de computação no Brasil é grande e utilizar ferramentas como o Scratch no início de disciplina de Algoritmos, por exemplo, pode motivar os alunos a permanecerem no curso e a instigarem [Salazar e Barvinsk 2015], por conseguir aplicar conceitos que estão sendo estudados em um 
V Congresso Brasileiro de Informática na Educação (CBIE 2016)

Anais do XXII Workshop de Informática na Escola (WIE 2016)

projeto, mesmo que seja em programação em blocos, pois eles conseguem interligar com conceitos vistos ou que serão vistos em linguagens utilizadas nos cursos, como C.

\section{Considerações Finais}

O Scratch apresenta-se como uma interessante ferramenta que permite ser aplicada em diferentes escolaridades para atingir objetivos distintos. Ela pode ser trabalhada junto aos conceitos defendidos na teoria do construcionismo de Papert que consiste em favorecer a criação do conhecimento do indivíduo a partir da interação entre as pessoas e por meio do desenvolvimento de um projeto em grupos e em algo que os indivíduos estejam interessados.

Durante as experiências pode-se observar trabalho em equipe, principalmente no projeto com as séries iniciais, em que uma turma não era habituada a fazer atividades em grupo, que fez com que a professora regente refletisse sobre a prática em sala de aula, conforme relatada as acadêmicas durante uma das aulas.

Nos projetos com o ensino superior e ensino técnico pode-se perceber interação entre as áreas no desenvolvimento dos projetos finais propostos no final do curso e oficinas, que resultou em projetos práticos que abordasse um determinado conteúdo e que pudesse ser aplicado na sala de aula no ensino básico.

No geral, além de ensinar instruções básicas de programação, favoreceu o raciocínio lógico e estruturado, habilidades em resolver problemas, visto que nas atividades iniciais pode-se observar maior dificuldade, o que foi superado, ao observarmos o desempenho em atividades finais mais complexas.

Espera-se que este trabalho sirva como uma das referências para atividades nas escolas utilizando a ferramenta Scratch, para que consiga adequar uma das ferramentas baseadas no Scratch para a faixa etária que deseja-se trabalhar.

Outras ferramentas serão avaliadas, e a construção de videoaulas de materiais para cada uma destas escolaridades estão em desenvolvimento.

\section{Referências}

Batista, E. J. S., Castro Jr, A., Larrea, A. A., e Bogarim, C. A. C. (2015, Outubro). Utilizando o Scratch como ferramenta de apoio para desenvolver o raciocínio lógico das crianças do ensino básico de uma forma multidisciplinar. In Anais do Workshop de Informática na Escola (Vol. 21, No. 1, p. 350).

Becker, F. (1994). O que é construtivismo. Série Idéias, 20, 87-93.

Bers, M. U., and Resnick, M. (2016). The official ScratchJr book.

Cardoso, R., Santos, O., and Gatti, D. C. (2015). "Revisão Sistemática de Objetos de Aprendizagem para o Ensino de Computação". Conferencias LACLO, 6(1), 389.

Cysneiros, P. G. (2008). "PAPERT, Seymour. A máquina das crianças: repensando a escola na era da informática". Tradução de Sandra Costa. Porto Alegre: Artes Médicas, 2008.

Freire, P. (2014). Educação como prática da liberdade. Editora Paz e Terra. 
V Congresso Brasileiro de Informática na Educação (CBIE 2016)

Anais do XXII Workshop de Informática na Escola (WIE 2016)

Maloney, J., Resnick, M., Rusk, N., Silverman, B., e Eastmond, E. (2010). The scratch programming language and environment. ACM Transactions on Computing Education (TOCE), 10(4), 16.

Oro, N., Pazinato, A., Teixeira, A., e Gross, Á. (2015, Outubro). Olimpíada de Programação de Computadores para Estudantes do Ensino Fundamental: A interdisciplinaridade por meio do Software Scratch. In Anais do Workshop de Informática na Escola (Vol. 21, No. 1, p. 102).

Rego, M. C. (2000). Vygotsky: uma perspectiva histórico cultural da educação. Editora Vozes Limitada.

Resnick, M., Ocko, S., and Papert, S. (1988). LEGO, Logo, and design. Children's Environments Quarterly, 14-18.

Resnick, M. (2014). Give P'sa chance: Projects, peers, passion, play. In Constructionism and creativity: Proceedings of the Third International Constructionism Conference. Austrian Computer Society, Vienna (pp. 13-20).

Salazar, R., Odakura, V., and Barvinski, C. (2015, October). Scratch no ensino superior: motivação. In Anais do Simpósio Brasileiro de Informática na Educação (Vol. 26, No. 1, p. 1293).

Souza, F. S. (2015). "Geração F5 - O Que Sabemos Sobre Ela?".Portal Educação. Acesso em 8 de junho de 2016. Disponível em: http://www.portaleducacao.com.br/pedagogia/artigos/62110/geracao-f5-o-quesabemos-sobre-ela\#ixzz4BNuR0IMg.

Tori, R. (2016). Tecnologia e Metodologia para uma Educação sem Distância. Revista em Rede, 2(2), 44-55.

Valente, J. A. (1997). Informática na educação: instrucionismo x construcionismo. Manuscrito não publicado, NIED: UNICAMP.

von Wangenheim, C. G., Nunes, V. R., e dos Santos, G. D. (2014). Ensino de Computação com SCRATCH no Ensino Fundamental-Um Estudo de Caso. Revista Brasileira de Informática na Educação, 22(03), 115 